\title{
Traduzindo em quadrinhos: tradução e análise da graphic novel Something is killing the Children, escrita por James Tynion IV e ilustrada por Werther Dell'edera
}

Ícaro Silva Gonçalves*

Aline Cantarotti**

\begin{abstract}
Resumo
Histórias em Quadrinhos, conhecidas também como HQs ou Graphic Novels, vem ganhando espaço em diferentes âmbitos sociais e culturais, devido a interesses, primeiramente, mercadológicos, elevando e popularizando esta forma de narrativa, influenciando a maneira com a qual a sua tradução é abordada. Considerando esta constatação, é importante que as singularidades desse meio sejam analisadas para que o processo tradutório possa abarcar as unicidades dessa mídia. Assim, foi realizada a tradução da HQ Something is Killing the Children, escrita por James Tynion IV, ilustrada por Werther Delledera e publicada pela BOOM!Studios, que conta a história de uma pequena cidade estadunidense atacada por monstros. Ela foi escolhida para enfatizar possíveis elementos culturais e, também, com o intuito de experienciar os desafios do processo tradutório encontrados na tradução de HQs, principalmente de terror. Através da análise deste e das observações levantadas no diário do tradutor, busca-se compreender os elementos que devem ser estudados durante a tradução de HQs, ressaltando a importância dos elementos gráficos e culturais para a sua fruição. Estas características foram estudadas durante a pesquisa, sendo ressaltadas as dificuldades e escolhas feitas no processo tradutório para um resultado coerente e fluido.
\end{abstract}

Palavras-chave: Tradução. História em quadrinhos. Imagem. Texto.

\footnotetext{
* Universidade Estadual de Maringá (UEM). Graduação em Inglês e Literaturas Correspondentes - Licenciatura e Bacharelado. Tradutor. https://orcid. org/0000-0002-6601-8428.

* Universidade Estadual de Maringá (UEM). Doutorado em Estudos Linguístico - Estudos da Tradução pela UNESP. Docente - Língua Inglesa/Tradução. https://orcid.org/0000-0003-1034-6825.
}

Cadernos CESPUC de Pesquisa. Série Ensaios. n.38, 10 Sem./2021, p. 154-173.

e-ISSN: 2358-3231 (OJS). Recebido em: 29/06/2021. Aceito em: 07/og/2021. 


\title{
Comic Translation: Translation and Analyses of the Graphic Novel Something is Killing the Children, written by James Tynion IV and ilustrated by Werther Dell'edera
}

\author{
Ícaro Silva Gonçalves \\ Aline Cantarotti
}

\begin{abstract}
Comic Books, also known as comics or Graphic Novels, have been gaining influence in different social and cultural spaces, mainly due to marketing interests, making this type of narrative more popular, impacting the way with which its translation is approached (ROSA, 2013). Considering this statement, it is important that the singularities of this medium are analyzed so that the translation process may encompass its uniqueness. Thus, the Graphic Novel Something is Killing the Children, written by James Tynion IV, illustrated by Werther Dell'edera and published by BOOM! Studios was translated. It tells the story of a small town in the United States that is being attacked by monsters. This narrative was chosen to emphasize possible cultural elements and, also, with the goal of experiencing the challenges in the translation process found in Graphic Novels, specially horror ones. Through this analysis and the observations raised in the translation journal, we seek to understand the elements that must be studied during the translation of Graphic Novels, highlighting the importance of the graphic and cultural elements for their enjoyment. These characteristics were studied during the research, reinforcing the difficulties and choices made in the translation process, aiming at a coherent and fluid result. Therefore, the theories of Aragão and Zavaglia (2010); Assis (2016); Bassnett and Lefevere (1992); Zanettin (2008; 2018), among others, were used as theoretical background.
\end{abstract}

Keywords: Translation. Graphic Novel. Image. Text.

Cadernos CESPUC de Pesquisa. Série Ensaios. n.38, 10 Sem./2021, p. 154-173. e-ISSN: 2358-3231 (OJS). Recebido em: 29/06/2021. Aceito em: 07/09/2021. 


\section{Introdução}

A história dos quadrinhos é bem diversa e - nos Estados Unidos principalmente - conturbada. De acordo com Federico Zanettin, no texto Comics in translation - an overview (2008), o primeiro registro considerado oficial desse tipo de narrativa ocorreu com Yellow Kid, em 1894 - apesar de que há registros de histórias contadas com o uso de imagens, que podem ser encontrados desde a pré-história. Desde então, jornais passaram a apresentar quadrinhos curtos, geralmente com cunho humorístico, fazendo, assim, com que essa mídia ganhasse o nome de comics. Posteriormente, abriu-se um leque ainda maior sobre possibilidades de gêneros a serem abarcados por histórias em quadrinhos, muitos deles envolvendo temas adultos, como mistérios, romances, histórias policiais e terror.

Devido aos assuntos abordados pelas histórias em quadrinhos começou, nos Estados Unidos, um movimento contra essa mídia, que foi taxada como "má influência" para jovens leitores. Assim, o livro Seduction of innocence foi escrito pelo psiquiatra estadunidense Frederic Wertham, em 1954, denunciando a suposta decadência moral incitada pelos quadrinhos. A pressão gerada por esse movimento fez com que editoras estadunidenses colocassem uma série de regras acerca dos assuntos e gêneros que poderiam ser abordados nos quadrinhos, chamadas de Comics Code Authority. Isso, previsivelmente, afetou essa indústria nos Estados Unidos - o próprio país em que essa mídia foi primeiro reportada -, fazendo com que a qualidade das histórias publicadas caísse. Esse código caiu em desuso já que, de acordo com Dr. Amy Kiste Nyberg (1998) no artigo Comics code history: The seal of approval, as editoras que estavam ativas durante o ápice dessa regulação - Marvel, DC Comics, Archie, entre outras - lentamente foram abandonando a agência regulatória, por perceberem que novas editoras independentes não faziam parte desse código e encontravam uma liberdade artística muito maior - o que também auxiliava a venda de quadrinhos. Por volta de 2011, todas as editoras passaram a regular o próprio conteúdo.

Assim, quadrinhos com narrativas mais complexas e temas voltados ao público adulto foram se tornando cada vez mais normais e não vistas apenas em editoras independentes ou criadas com esse objetivo específico, como a Vertigo, criada pela DC Comics com intuito de publicar quadrinhos

Traduzindo em quadrinhos: tradução e análise da graphic novel Something is 156 killing the Children, escrita por James Tynion IV e ilustrada porWerther Dell'edera 
que não passariam pelo código, como Swamp Thing, de Alan Moore (1996). Atualmente, essa é uma indústria muito diversificada em questões temáticas, artísticas e de público leitor.

Dessa forma, há três elementos principais a serem considerados na tradução de quadrinhos, segundo Zanettin (2008), que são: gênero, público receptor, produção e distribuição. Na questão do gênero, o autor os divide nas seguintes categorias gerais: comédia, épicos e tragédia. A comédia seria o gênero mais associado aos quadrinhos, pois eles começaram a ser publicados como tiras curtas e cômicas em jornais e pode envolver desde histórias mais infantis (um exemplo muito comum no Brasil é A Turma da Mônica, de Maurício de Souza) até sátiras políticas e um humor mais maduro, como podemos ver em algumas das tiras da quadrinista Laerte.

O gênero épico envolve um grande leque de subgêneros, já que se relaciona a narrativas mais extensas e complexas. Assim, histórias de superheróis, terror, mistério, romance e Graphic Novels, em geral (publicações mais longas de quadrinhos que focam geralmente em uma história ou personagem, contrastando com o modelo serializado) fazem parte desse gênero épico. Por fim, a tragédia é mais recente em quadrinhos Ocidentais, porém, devido à popularidade e diversidade de narrativas possíveis pelo mangá, já é um gênero muito explorado na Ásia, principalmente no Japão.

$\mathrm{Na}$ questão do público alvo, é considerado, além do gênero da história em quadrinhos, faixa etária, relações de gênero, ocupação, entre outros. A maior diferença é marcada na questão da faixa etária, uma vez que o vocabulário utilizado para traduzir uma história para um público mais maduro pode ser impróprio para um grupo mais jovem, pela complexidade da fala e uso de linguagem vulgar, por exemplo.

Sobre a produção e distribuição, é considerado o meio pelo qual a história em quadrinhos será distribuída. Elas podem ser encontradas em jornais e revistas em tiras curtas, em pequenas histórias serializadas e semanais em um livreto ou até em uma coletânea com vários capítulos, como são as Graphic Novels. Atualmente, com o advento da Internet, também é possível encontrar essas histórias em websites, pagos ou não, disponíveis para o público geral.

Assim, na tradução de narrativas em quadrinhos, todas essas características devem ser consideradas. Além disso, elementos gráficos como a arte, a posição dos balões de fala, pensamento ou explicação, 
onomatopeias e lettering (a maneira com que as palavras são escritas e estilizadas nos quadrinhos) são elementos muito importantes da composição da HQ e devem ser observados com cuidado durante o processo tradutório. Portanto, esses elementos que diferenciam a história em quadrinhos de outras narrativas devem ser cuidados e ressaltados durante a tradução.

Segundo Assis (2016), o tradutor de quadrinhos tem acesso apenas à parte escrita da história, ainda que, pela natureza do texto, muito da narrativa depende da interação entre o que está sendo falado pelas personagens e mostrado nas imagens. Desta forma, o trabalho de adaptação deve ser feito com muita atenção à união desses elementos.

Entre as Graphic Novels consideradas, foi escolhida a HQ de terror Something is killing the children (2019), escrita por James Tynion IV e desenhada por Werther Delledera. Ela conta a história de uma pequena cidade nos Estados Unidos com um trágico fenômeno: várias crianças estão desaparecendo e morrendo de maneira violenta. Nenhum dos adultos sabe o que está acontecendo, apenas as crianças conseguem ver os monstros que as aterrorizam. Somos apresentados, então, à Erica Slaughter, uma mulher misteriosa, capaz de ver e lutar contra essas criaturas e determinada em salvar os habitantes da cidade.

Para realizar a tradução, o programa OmegaT foi utilizado, com o intuito de auxiliar a tradução da transcrição dessa narrativa. No processo, foram considerados os elementos gráficos da história, como balões de conversa, interação da imagem com a parte escrita, onomatopeias e o lettering. Isso torna a tradução mais condizente com a narrativa, além de possibilitar o projeto gráfico de inserir a tradução nos quadrinhos, já que a compreensão desse tipo de narrativa depende da interação entre imagem e texto. As teorias utilizadas como embasamento, que serão expandidas no tópico sobre referenciais teóricos, focam em elementos culturais e como estes podem influenciar a tradução, ressaltando as observações de Bassnett e Lefevere (1992) sobre os impactos da cultura no processo tradutório e a análise proposta por Zanettin (2018) na discussão acerca da história e os movimentos tradutórios de histórias em quadrinhos, ressaltando os elementos intersemióticos dessa mídia. Então, de acordo com o autor, quatro componentes do processo tradutório de HQs: as características da cultura fonte e alvo; ou seja, como histórias em quadrinhos são entendidas em cada uma dessas instâncias; a história das HQs e suas traduções, considerando 
o papel das editoras e a questão da censura; a tradução e a identidade sociopolítica, através de uma comparação da narrativa construída na língua fonte e as mudanças pelas quais passou na língua alvo; e, por fim, uma análise dos componentes intersemióticos na tradução e adaptação da narrativa em Graphic Novels, uma vez que, de acordo com Mitchell (2014, apud ZANETTIN, 2018, p. 452), seria uma "transmídia", extrapolando os limites antes impostos.

\section{Referencial Teórico}

Aragão e Zavaglia (2010) refletem sobre a interação entre texto e imagem. Em seu estudo, as autoras também discorrem sobre as influências ideológicas e culturais na escrita, tradução e até mesmo no processo de leitura das Graphic Novels. A partir das suas considerações, Aragão e Zavaglia estudam as dificuldades postas pela tradução de quadrinhos, pois, "Esses problemas são reforçados pela presença da imagem, que muitas vezes limita as possibilidades de tradução e, diferentemente do texto, com frequência não pode ser manipulada pelo tradutor." (ARAGÃO; ZAVAGLIA, 2010, p.441).

Assis (2016) observa elementos culturais específicos e como estes podem afetar a tradução de HQs. O autor também levanta certas especificidades encontradas nessa mídia e que devem ser consideradas durante a sua tradução e análise. $\mathrm{O}$ autor propõe, ainda, cinco pontos que devem ser considerados e expandidos ao estudar o papel do tradutor de HQs:

Inicialmente, propõe-se cinco especificidades, a serem analisadas à frente:

1. Ingerência do tradutor reduzida às unidades de material linguístico; 2 . Indissolubilidade da mancha gráfica; 3. Indissolubilidade das quebras verbais; 4 . Documento de tradução = roteiro para letreirista; 5 . O letreirista como cotradutor. (ASSIS, 2016, p.26). 
Considerando a perspectiva cultural utilizada para analisar o processo tradutório e as adaptações realizadas, estamos embasados em Bassnett e Lefevere (1992), os quais observam a interação entre cultura e tradução. Aqui, tem-se a tradução como reescrita e os impactos que esse processo realiza sobre determinada cultura. Também é considerado o público da obra traduzida, já que, segundo os autores: “[...] a tradução não é apenas um processo que ocorre na mente dos tradutores. Leitores decidem se a tradução será aceita ou rejeitada. Diferentes tipos de leitores requerem diferentes tipos de tradução" (BASSNETT, LEFEVERE, 1992, p. 5, tradução nossa). ${ }^{1}$ Portanto, processos tradutórios devem considerar os seus objetivos, o que será necessário ser adaptado, mantido ou modificado para que os leitores da tradução possam desfrutar da obra de maneira completa.

Por fim, Zanettin $(2008 ; 2018)$ considera a tradução de HQs em linhas gerais e se aprofunda em elementos históricos, atuais e os futuros possíveis para a tradução de histórias em quadrinhos. De acordo com o autor, a tradução de quadrinhos é o que possibilitou a cultura criada pelas HQs, que influenciam a chamada pop culture, e aproxima culturas que, antes, eram muito distantes. Nesse sentido, Zanettin (2018) afirma:

Tradução tem um papel extremamente importante no desenvolvimento da cultura de quadrinhos ao redor do mundo, dois momentos que definem isso são a Idade de Ouro dos quadrinhos Norte Americanos por volta de 1930 e a popularização dos mangás japoneses em 1990. ${ }^{2}$ (ZANETTIN, 2018, p.446, tradução nossa).

Considerando essa afirmação, é interessante notar que essa popularização dos mangás também foi possível devido às características únicas das HQs, principalmente por meio das imagens. Assim, através da flexibilidade e dinamicidade dessa forma narrativa pela presença de imagens como uma parte integral e característica desse meio, surge uma maneira de comunicação cultural única. Mesmo quando não há a compreensão do texto escrito, muitas vezes o geral da história pode ser compreendido ao acompanhar as imagens. A tradução do texto, nesse caso, permite o entendimento integral da obra e faz com que a quantidade de pessoas

\footnotetext{
1 "Translation then, is not just a process that happens in the translator's head. Readers decide to accept or reject translations. Different types of reader will require different types of translation" (BASSNETT, LEFEVERE, 1992, p. 5)

2 "Translation has played a paramount role in the development of comics cultures around the world, two defining moments being the Golden Age of North American comics around the 1930s and the height of Japanese manga in the 1990s." (ZANETTIN, 2018, p.446)
}

Traduzindo em quadrinhos: tradução e análise da graphic novel Something is 160 killing the Children, escrita por James Tynion IV e ilustrada porWerther Dell'edera 
que entram em contato com a narrativa seja muito maior. Ao considerar a questão dos mangás, muitas histórias que se tornaram canonizadas na cultura popular se originaram nesse meio, como Dragon Ball (TORIYAMA, 1984-1995), Sailor Moon (TAKEUCHI, 1991-1997), Akira (OTOMO, 19821990), entre outros que influenciam não só a mídia Japonesa, mas também muitas narrativas ocidentais, principalmente ao considerar a influência que Akira teve em filmes de ficção científica, como Blade Runner (SCOTT, 1982), entre outros.

\section{Metodologia}

O processo de tradução da história em quadrinhos foi constituído, primeiramente, pela seleção de textos teóricos sobre o assunto em questão. Depois, foi realizada a transcrição dos elementos escritos nos quadros que envolvem diálogos, onomatopeias e, às vezes, balões explicativos - do primeiro volume, que envolve os capítulos de 1 a 5. Posteriormente, foi feita a tradução da transcrição. Além disso, foram criados um glossário e um diário de tradução simultaneamente ao processo tradutório, com o intuito de auxiliar o processo como um todo. A tradução e criação de glossário, além de uma memória de tradução, ocorreram através do uso do programa OmegaT.

Além do programa mencionado, para realizar a tradução e a sua posterior análise houve o estudo do referencial teórico selecionado e referido anteriormente e o uso, como suporte, de dicionários online, como o Linguee, Cambridge Dictionary, Merriam - Webster e Sinônimos.

Para a organização do processo tradutório, foi estipulado um cronograma que se estendeu por um período de seis meses (setembro 2020 até abril 2021). O processo foi dividido nas seguintes etapas: levantamento bibliográfico, que envolveu a busca e leitura de textos relevantes ao assunto em questão; transcrição da HQ de modo que onde toda a parte escrita falas, placas, onomatopeias, etc. - foi reunida em um arquivo para facilitar a tradução do texto; tradução da transcrição, ou seja, a prática tradutória em si; aplicação do texto traduzido na HQ, realizando, assim, o projeto gráfico para que a narrativa seja aproveitada na sua completude; análise da 
tradução, a observação e ponderação sobre o processo tradutório; revisão final, tanto do texto quanto do projeto gráfico realizado; escrita final deste estudo.

Quanto às atividades desenvolvidas durante o processo tradutório, a prática não seguiu o cronograma à risca. O levantamento bibliográfico foi um processo constante, realizado de acordo com a necessidade de embasamento teórico. A transcrição e a tradução ocorreram simultaneamente, cada capítulo foi transcrito e traduzido. Depois, as traduções foram compiladas em um único arquivo para a revisão e padronização dos termos escolhidos e da linguagem utilizada no texto. O projeto gráfico foi realizado na medida do possível, focando nas falas das personagens devido às limitações do tradutor quanto à recriação dos elementos gráficos, já que algumas das partes escritas ocorrem sobrepostas a uma ilustração. Assim, após esse projeto gráfico, foi realizada uma última revisão para garantir a harmonia entre o texto escrito e as imagens.

\section{Análise e Discussão}

Narrativas gráficas acompanharam o desenvolvimento da comunicação humana - a primeira maneira de se comunicar foi através de ilustrações contando histórias. É possível entender a escrita como um desenvolvimento natural a partir disso, tornando-se necessária para exprimir narrativas que não conseguiam ser completamente compreendidas apenas em desenhos (histórias com personagens, por exemplo). Assim, histórias em quadrinhos mesclam ambos os aspectos, criando uma série de símbolos e lógica específica para construir uma narrativa, como afirma Zanettin (2018, p.445, tradução nossa):

[...]quadrinhos, como um tipo de narrativa gráfica, dependem de uma série de convenções e símbolos específicos que são o resultado de uma história e evoluções distintas através dos tempos e, até certo ponto, trocas culturais através da tradução. ${ }^{3}$ (ZANETTIN2018, p.445, tradução nossa).

\footnotetext{
3 "[...] comics as a type of graphic narrative rely on a specific set of conventions and symbols which is the result of a specific history and evolution over time and, to a large extent, cultural exchange through translation."(ZANETTIN, 2018, p.445)
}

Traduzindo em quadrinhos: tradução e análise da graphic novel Something is 162 killing the Children, escrita por James Tynion IV e ilustrada por Werther Dell'edera 
Em uma perspectiva linguística, o entendimento de quadrinhos depende dos elementos que ele contém, com significados socialmente convencionados. Ou seja, a ordem e sentido das palavras, as imagens apresentadas, os símbolos não escritos que representam o estado da personagem (emanata), as onomatopeias, o lettering, a estilização dos balões de fala e pensamento. Estes elementos devem ser compreendidos na sua interação completa, ou seja, eles se complementam e dão sentido ao quadrinho. Nem sempre todos esses elementos estarão presentes e, nesse caso, deve haver alguma maneira de compensar a sua falta (por exemplo, alguns quadrinhos da Turma da Mônica não apresentam diálogos, mas o que aparece marcado são as expressões, emanatas, e as imagens nos balões de fala. Assim, a história é contada sem que haja o elemento escrito). Isso é reforçado por Zanettin (2018), que afirma:

Características prototípicas semióticas, por vezes referidas como o vocabulário e gramática de quadrinhos, incluem a combinação de imagens e palavras nos painéis e um leque de emanatas, códigos visuais convencionais usados como atalhos para representar elementos como diálogo e pensamento, música, som e movimento. (ZANETTIN, 2018, p.445-446; tradução nossa). ${ }^{4}$

Além dessa perspectiva linguística, histórias contadas a partir da interação entre imagem e texto se desenvolveram com a cultura. Durante o século XX, principalmente após a Primeira Guerra Mundial, quadrinhos com contextos políticos começaram a ganhar cada vez mais espaço Isso ocorre, por exemplo, nos quadrinhos do Capitão América, criado por Jack Kirby e Joe Simon, antes dos Estados Unidos realmente entrar na Segunda Guerra Mundial. Kirby e Simon eram judeus e, através dessa personagem, demandaram uma postura mais assertiva dos Estados Unidos contra o nazismo. Por meio da tradução, é possível conhecer diferentes culturas, problemas e singularidades específicas de cada uma delas. A tradução permite o entendimento de outras vivências e, com isso, pode promover a empatia entre diferentes realidades. Nas histórias em quadrinhos, considerando os temas muitas vezes abordados, pode-se dizer que eles permitem a desconstrução de conceitos que são herdados da sociedade.

4 "Prototypical semiotic features, sometimes referred to as the vocabulary and grammar of comics, include the combination of images and words within panels and an array of emanata, conventional visual codes used as shorthands to represent invisible elements such as speech and thought, music, noise and motion" (ZANETTIN, 2018, p.445-446) 
Além disso, muitos apresentam críticas ácidas a certos comportamentos como nos casos de Watchmen, na qual se expõe o abuso de poder de pessoas que se veem e se entendem como superiores; ou na crítica a governos fascistas presente em $V$ for Vendetta; $X$-men, que pode ser entendido como uma metáfora para exclusão de minorias - principalmente pessoas não brancas e a comunidade LGBTQIA+ —; entre outros. Há também as obras que abordam assuntos delicados que são considerados tabu tal como Jessica Jones, que lida com estupro e TEPT gerado por relacionamentos abusivos, perda de agência e controle sobre o próprio corpo; Maus, considerada uma alegoria sobre a experiência dos judeus durante a Segunda Guerra Mundial e Persépolis - história semiautobiográfica de uma garota se tornando adolescente durante a Revolução Islâmica no Irã; etc..Considerando a interação entre tradução e cultura segundo Bassnett e Lefevere (1992), a tradução “[...] não é apenas um processo que ocorre na mente do tradutor. Leitores decidem a aceitação ou rejeição da tradução. Diferentes tipos de leitores requerem diferentes tipos de tradução."5 (BASSNETT; LEFEVERE, 1992, p.5; tradução nossa). Assim, a tradução deve visar o público que irá consumir o que está sendo traduzido. Tal consideração influencia, também, as escolhas semânticas, já que ela deve ser compreendida e aceita pelo público da cultura receptora. Ou seja, "traduções não são feitas no vácuo." (BASSNETT; LEFEVERE, 1992, p.14; tradução nossa), portanto, traduções devem ser entendidas e tidas dentro de um contexto linguístico e cultural.

Primeiro, a tradução permite interação entre culturas que, muitas vezes, não tem nada - ou têm muito pouco - em comum. Tem-se, então, a questão sobre domesticação e estrangeirização, que são duas estratégias de tradução que influenciarão a maneira com que o texto será consumido e compreendido pelos receptores da tradução, conforme Venutti (1995). Assim, o processo de tradução deve considerar todos os aspectos e contextos socioculturais do texto fonte e alvo, e como a narrativa deve ser abordada e importada. O tradutor deve estar ciente das diferenças e semelhanças culturais, além das suas ideologias, experiências e conhecimento de mundo, já que isso pode influenciar a abordagem que é tomada na realização da tradução.

\footnotetext{
5 "[...]is not just a process that happens in the translator's head. Readers decide to accept or reject translations. Different types of reader will require different types of translation”(BASSNETT, LEFEVERE, 1992, p.5)

6 “Translations are not made in a vacuum."(BASSNETT, LEFEVERE, 1992, p.14)
}

Traduzindo em quadrinhos: tradução e análise da graphic novel Something is 164 killing the Children, escrita por James Tynion IV e ilustrada por Werther Dell'edera 
Quanto a isso, a tradução de quadrinhos por muito tempo envolveu, até certo ponto, adaptação da parte gráfica e narrativa para se encaixar nos ideais da cultura para qual era traduzida, como exemplifica Zanettin ao analisar as traduções de HQs no início do século XX:

Como a palavra escrita é considerada superior, por um longo tempo, imagens foram tratadas apenas como ilustrações de histórias verbais e narrativas gráficas eram consideradas culturalmente inferiores [...] Assim, quando quadrinhos americanos começaram a ganhar espaço no mercado (todos geralmente pirateados e publicados sem créditos), eles eram altamente manipulados para se conformarem ao formato e leitura europeu. ${ }^{7}$ (ZANETTIN, 2018, p. 448, tradução nossa).

Segundo o autor, no contexto europeu, os quadrinhos eram vistos como uma forma "menor" de narrativa. Assim, quando as HQs estadunidenses passaram a ser traduzidas para países da Europa, o processo abarcava também a alteração gráfica das narrativas, como apagamento dos balões, relocação das falas e adaptação da "moral" da história, já que os quadrinhos europeus apresentavam sempre conteúdo pedagógico. Contudo, isso mudou com o tempo e, como os quadrinhos se tornavam cada vez mais parte da cultura mainstream, a necessidade de priorizar um formato dinâmico, valorizando a imagem tanto quanto o texto foi percebida, fazendo com que ocorresse uma adaptação cultural aos quadrinhos.

Analisar tradução de quadrinhos, de acordo com Zanettin (2018), é analisar tradução intersemiótica. Devido às suas características únicas, histórias em quadrinhos podem ser compreendidas como "transmídia", ou seja, envolve diferentes níveis de compreensão e interpretação, já que a narrativa é construída pela interação de imagem e texto, de forma que estes são necessários para que a história seja contada e lida na sua integralidade. É traduzível e transicional (MITCHELL, 2014, p.259, apud ZANETTIN, 2018, p.453).

Assim, histórias em quadrinhos dependem da imagem e do texto para serem entendidas. No processo de tradução, dessa forma, é necessário

\footnotetext{
7 "Because of the perceived superiority of the written word, for a long while images were treated only as illustrations of verbal stories, and graphic narratives were considered as culturally inferior [...]. Thus, when American comics begun to be preferably sourced over other foreign products (all usually pirated and published without attribution), they were heavily manipulated in order to conform to the European format and readership." (ZANETTIN, 2018, p. 448)
} 
considerar como esses dois elementos se conectam, pois a compreensão do texto depende da compreensão da imagem e vice-versa. É comum que referências textuais ou imagéticas sejam apontadas de outro meio, de maneira a dinamizar, representar e caracterizar as histórias em quadrinhos. Contudo, o tradutor só tem acesso ao texto, fazendo com que ele sempre se adapte às imagens para construir sentido (ASSIS, 2016, p.29).

Entre o texto e a imagem, tem-se o letreiramento, ou lettering, ou seja, a fonte usada no texto e essa estilização expressa as individualidades das personagens ou indicações de onomatopeias, placas, entre outros. É muito comum ter personagens não humanas cujas falas não usam a mesma fonte ou a mesma cor que as outras personagens. Em Something is killing the children (TYNION; DELL'EDERA, 2019), uma das personagens é um polvo de pelúcia e, devido a isso, para reforçar que essa é uma personagem não humana, as suas falas levam uma fonte diferente, além de usar outras cores (um roxo levemente azulado) e os balões também são estilizados de uma maneira diferente, como é possível observar no exemplo abaixo:

\section{Figura 1 - Exemplos de letreiramento}
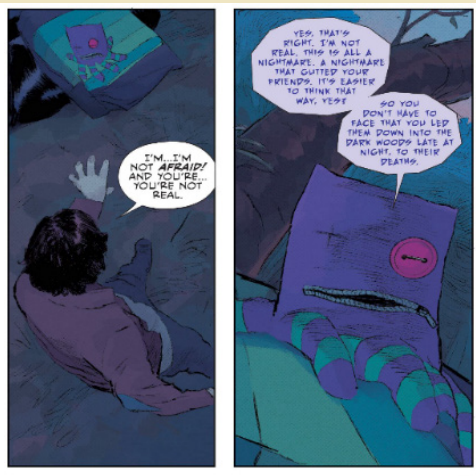

Exemplo 1.1: versão em inglês de letreiramento, comparação da fala de personagem humana e não humana
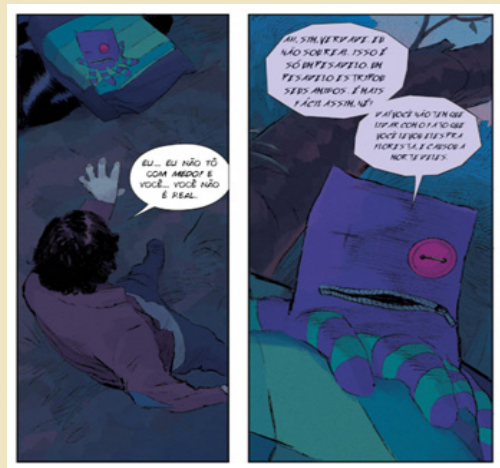

Exemplo 1.2: versão em português de letreiramento, comparação da fala de personagem humana e não humana

Fonte: TYNION;DELLEDERA, 2019, vol.1, no 2, p. 16.)

Tradução: os autores

Traduzindo em quadrinhos: tradução e análise da graphic novel Something is 
A imagem acima demonstra o que foi dito no parágrafo anterior: no quadrinho da esquerda, há uma personagem humana, o balão de fala é oval, apresenta fundo branco e as letras são pretas. Já na direita, há a fala do polvo de pelúcia (a personagem não humana) e é possível notar que o seu balão de fala é diferente. $\mathrm{O}$ balão possui ângulos, sua cor é lilás, as letras são azuis e a fonte difere daquela usada para personagens humanas. Considerando todos esses elementos, buscou-se, na tradução e no projeto gráfico, uma adaptação desses elementos para os quadrinhos traduzidos.

Reforça-se, aqui, o conceito da interação entre texto e imagem. Na tradução, houve a aproximação do projeto gráfico, além da tradução do texto, com intuito de manter as características das personagens. Segundo Barthes (1990):

Aqui a palavra (na maioria das vezes um trecho de diálogo) e a imagem têm uma relação de complementaridade; as palavras são, então, fragmentos de um sistema mais geral, assim como as imagens, e a unidade da mensagem é feita em um nível superior: o da história, o da anedota, o da diegese. (BARTHES, 1990, p.33-34, apud ARAGÃO, ZAVAGLIA, 2010, p.439)

Assim, histórias em quadrinhos se formam pela complementação que ocorre entre texto e imagem dentro dessa forma de narrativa. Além disso, esses elementos são organizados de forma sequencial, construindo, assim, uma lógica interna da história que está sendo contada, composta pela ordem dos quadrinhos nas páginas e a numeração destas (ZANETTIN, 2018).

Segundo Bassnett e Lefevere (1992), a tradução pode ser vista como reescrita. Dessa forma, a cultura para a qual se traduz influencia o processo, as ideologias e a construção da narrativa em outra língua. Nos quadrinhos, além do texto, as imagens também demonstram referências culturais. Contudo, o tradutor não tem acesso aos elementos gráficos, portanto, o processo de tradução da parte textual deve se adaptar às imagens, de modo que faça sentido no contexto apresentado, de acordo com Assis (2016). Por exemplo, caso haja alguma referência à imagem no texto, ela deve ser adaptada para que fique adequada na tradução ou para manter o sentido na cultura alvo. Isso também pode ocorrer com trocadilhos e piadas, que 
devem ser adaptados para que o ritmo cômico seja mantido, as ações e reações façam sentido e a narrativa seja fluida.

No caso de Something is killing the children (TYNION; DELL'EDERA, 2019), essas referências e momentos cômicos não aparecem com tanta frequência, mesmo que estejam presentes. A maior parte dos diálogos foca na construção trágica da história, desenvolvendo a lógica dentro deste universo (ou seja, as regras, como a realidade se dá dentro dessa narrativa) e os efeitos dos eventos da narrativa na vida das personagens. Durante o processo de tradução, foram considerados elementos linguísticos e culturais, buscando, dessa forma, traduzir a narrativa de uma maneira que despertasse o interesse e aproximasse o universo construído pela HQ aos leitores alvo.

Figura 2 - Referência Cultural

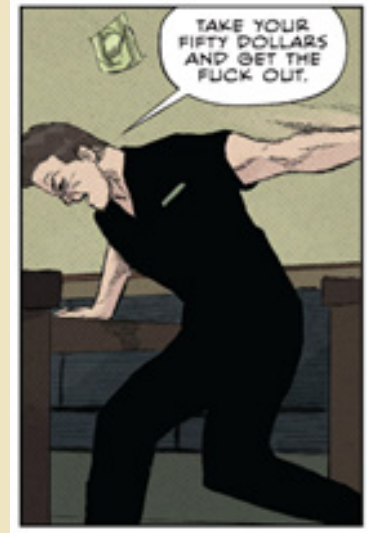

Exemplo 2.1: versão em inglês sem referência cultural

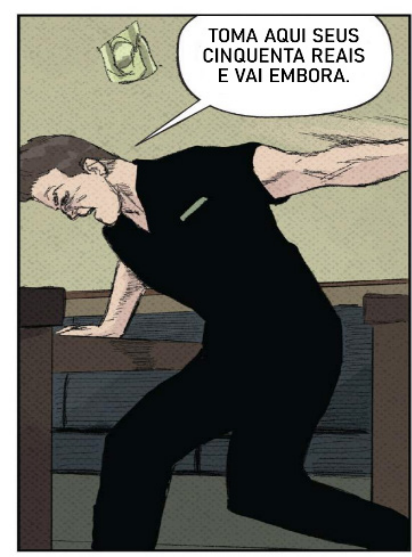

Exemplo 2.2: versão traduzida para o português com referência cultural

Fonte: TYNION; DELL'EDERA 2019, vol.1, nº 2, p. 16.

Tradução: os autores

Comparando ambas as imagens, observa-se que, assim como é apontado pelos títulos, houve a introdução de uma referência cultural na tradução, que se deu pela citação de parte do refrão da música "50 reais", da dupla Maiara \& Maraísa. Essa escolha foi feita para aproximar o público da cultura alvo da narrativa, apesar da inserção de um momento cômico destoar do momento da história, ela foi feita para engajar os leitores ao 
aproximar o universo da HQ da realidade conhecida por eles. Essa escolha foi baseada no conceito de tradução como reescrita segundo Bassnett e Lefevere (1992), já mencionado anteriormente e transcrito a seguir:

Tradução é, claro, uma reescrita do texto original. Todas as reescritas, quaisquer suas intenções, refletem uma certa ideologia e poética e, dessa forma, manipulam a literatura para funcionar em uma certa sociedade de uma certa forma.[...] Reescrita pode introduzir novos conceitos, gêneros, sistemas e a história da tradução é, também, a história da inovação literária, da formação de poder de uma cultura sobre outra. (BASSNETT; LEFEVERE, 2019, p.XI; tradução nossa). ${ }^{8}$

Ao pensar em tradução como reescrita, conforme os conceitos apresentados por Basnette Lefevere (1992), tem-se uma maior liberdade para moldar o texto à forma que melhor se adaptará aos objetivos da tradução. Por exemplo, colocar referências ou especificidades culturais que não estão presentes no texto em inglês, como ocorreu na tradução da HQ Something is killing the children (2019), principalmente no excerto ressaltado acima. Assim, através da tradução, a história deve ser reentendida, repensada, recontextualizada e, muitas vezes, atualizada para agradar a um público específico.

As adaptações e referências, as escolhas semânticas que aproximam a variação linguística utilizada na tradução dos quadrinhos à variação mais comum na fala, são parte do processo tradutório - e, consequentemente, de reescrita - da HQ. Quanto às falas das personagens, a tradução buscou aproximar os diálogos à língua falada, tornando, dessa forma, as trocas e interações mais fluidas. Além disso, também foram marcadas as diferenças sociais e de idade das personagens por meio das suas falas, o que reforça a caracterização das personagens, e as aproximando da realidade dos leitores. Para tal, além das variações linguísticas, foram também considerados elementos tais como gírias e palavrões. Esses elementos tornam os diálogos mais realistas e reforçam o tom da narrativa, principalmente ao considerar o uso de palavrões e linguagem chula, já que, dependendo do seu uso, esse tipo de vocabulário intensifica os sentimentos das personagens em certas situações.

\footnotetext{
8 "Translation is, of course, a rewriting of an original text. All rewritings, whatever their intention, reflect a certain ideology and a poetics and as such manipulate literature to function in a given society in a given way. [...] Rewritings can introduce new concepts, new genres, new devices, and the history of translation is the history also of literary innovation, of the shaping power of one culture upon another." (BASSNETT; LEFEVERE, 2019, p.XI)
} 
Figura 3: versão traduzida - uso de palavrão

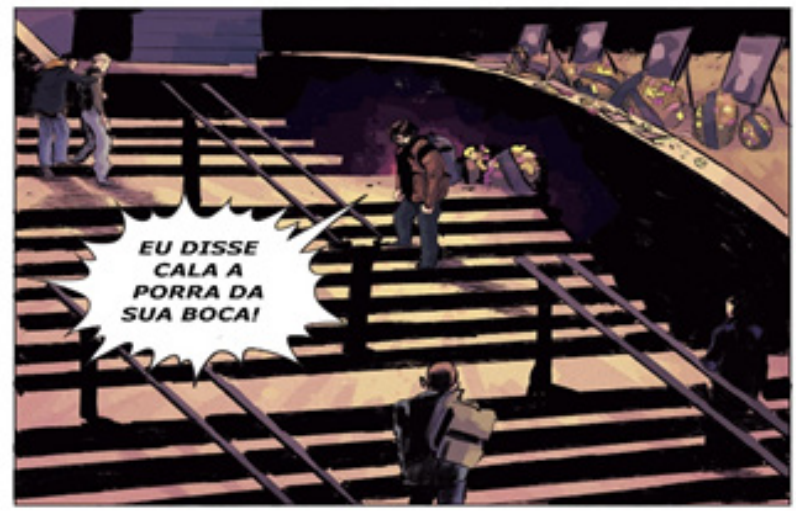

Fonte: TYNION; DELL'EDERA, 2019, vol.1, no 1, p.14.

Tradução: os autores.

Figura 4: versão traduzida - diferentes variações linguísticas

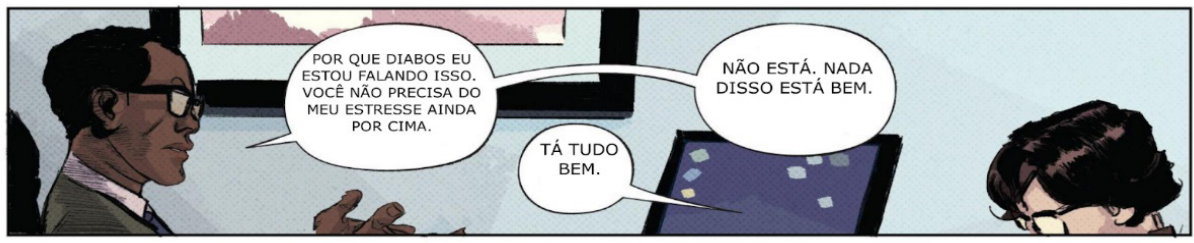

Fonte: TYNION; DELL'EDERA, 2019, vol.1, no 1, p.15.

Tradução: os autores.

Figura 5: versão traduzida - uso de gíria

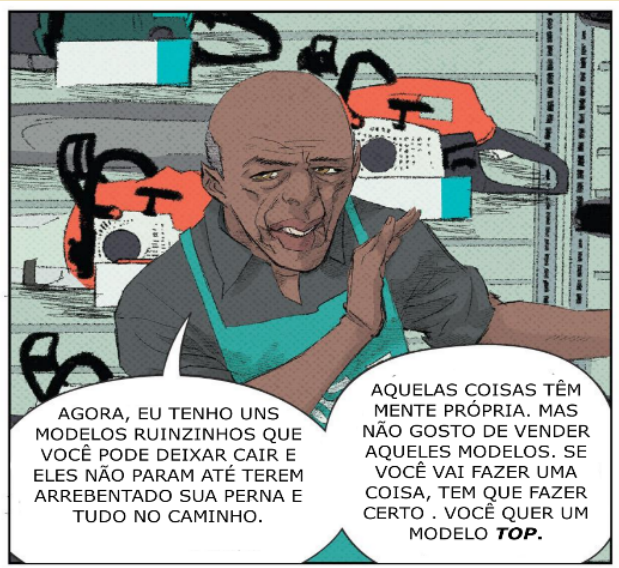

Fonte: TYNION; DELL'EDERA, 2019, vol.4, nº 1, p.1. Tradução: os autores.

Traduzindo em quadrinhos: tradução e análise da graphic novel Something is 
Como é possível observar, as escolhas foram feitas com o intuito de aproximar a história da realidade linguística dos leitores. Isso contextualiza, culturalmente, o texto e facilita a identificação dos leitores com as personagens e, assim, o aproveitamento da narrativa. Essas decisões e adaptações são feitas sempre considerando a maneira com a qual o texto interage com a imagem e como se complementam, já que, como demonstrado anteriormente, a leitura de histórias em quadrinhos depende da relação entre texto e imagem, visando a sua sincronia. No processo de tradução, dessa forma, há uma "[...]ênfase à relação de complementaridade semântica entre palavras e imagens. Essa interdependência configura, como em outras formas de mídia, a natureza das HQ, que são sistemas sincréticos[...]" (ARAGÃO; ZAVAGLIA, 2010 p.438).

Retoma-se aqui, portanto, a ideia de Bassnett e Lefevere (1992) sobre tradução e cultura, ao considerar que a tradução, assim como a obra em si, reflete a realidade na qual é criada, tanto ao nível semântico e linguístico quanto cultural. As escolhas de palavras e referências culturais dependem do contexto histórico social no qual essa narrativa está sendo contada e traduzida. Nas histórias em quadrinhos essa influência transparece não apenas no texto, mas nas ilustrações, tanto na questão do estilo de ilustração e das cores utilizadas até nos elementos culturais que aparecem nas imagens. Assim, como o tradutor tem acesso apenas ao texto, a tradução deve ser pensada de tal maneira que faça sentido no contexto criado pelas imagens, complementando-as e, assim, reescrevendo a narrativa.

\section{Considerações Finais}

A realização desse processo de tradução do primeiro volume da história em quadrinhos Something is killing the children (TYNION, 2019) e a posterior análise deste processo tivemos, como procuramos apresentar, o embasamento em teorias de Aragão e Zavaglia (2010), na análise da interação entre texto e imagem; Assis (2016), o qual observa elementos culturais específicos e como estes podem afetar a tradução de HQs; Bassnett e Lefevere (1992); Zanettin (2008 e 2018), ao estudar a tradução de HQs em 
linhas gerais e se aprofundar em elementos históricos, atuais e os futuros possíveis para a tradução de HQs.

Assim, o processo tradutório se iniciou com a escolha do material a ser traduzido. A Graphic Novel em questão foi escolhida devido ao interesse pessoal de um dos tradutores quanto à narrativa e o gênero terror, além do fato de que não há uma tradução oficial deste material em português.

Para realizar a parte prática da tradução, foi primeiramente realizada a transcrição do primeiro volume Something is killing the children (2019), dividido em cinco capítulos. Assim, cada capítulo foi transcrito - tanto os balões de fala quanto os outros elementos escritos, como placas, sinais, onomatopeias, entre outros - e, posteriormente, traduzido. A tradução foi realizada com o auxílio das ferramentas MemoQ e, depois, OmegaT. Ela foi, então, compilada em um arquivo, revisada e padronizada para a realização do projeto gráfico - através da ferramenta de edição GIMP - que consistiu na transcrição do texto traduzido para os quadrinhos. Esta etapa foi realizada com o objetivo de observar e analisar a interação entre a tradução do texto e as imagens que formam a narrativa, já que estes elementos são essenciais para a compreensão total da história construída.

Como foi estabelecido neste estudo através das análises das teorias estudadas, a tradução de histórias em quadrinhos envolve elementos escritos e imagéticos. Assim, é necessário, para que a tradução seja completa, estabelecer a sincronia entre o texto traduzido - a parte da narrativa sobre a qual o tradutor realiza o processo de tradução - e a ilustração, que complementa a história. Portanto, o processo tradutório deve sempre considerar a interação entre texto e imagem para que a narrativa seja compreendida.

Considerando a perspectiva cultural, no aspecto linguístico, buscouse a aproximação do texto à linguagem coloquial, conferindo mais realismo e fluidez à narrativa. Dessa forma, expressões como "tá", "tô", "cê" foram utilizadas, já que a maioria das personagens são adolescentes ou jovens e, consequentemente, expressões coloquiais, além de gírias e linguagem chula, são mais condizentes com a personalidade e faixa etária de grande parte das personagens.

O processo de tradução de quadrinhos requer uma análise tanto da parte escrita quanto das ilustrações, pois são elementos de extrema importância para a caracterização e compreensão deste meio narrativo, já 
que a história só pode ser entendida na sua completude através da interação e união destes elementos. Dessa forma, estes elementos, além de outras características e referências culturais, aspectos linguísticos e de construção de personagens, são componentes que devem ser considerados na tradução de histórias em quadrinhos, já que são, também, o que constituem e caracterizam as Graphic Novels.

\section{Referências}

ARAGÃO, Sabrina; ZAVAGLIA, Adriana. História em quadrinhos: imagem e texto em tradução. TradTerm, São Paulo, v.16, 2010, p. 435 - 463 ASSIS, Érico Gonçalves. Especificidades da tradução em quadrinhos: abordagem inicial. TradTerm, São Paulo, v. 27, setembro 2016, pp. 15-37

BASSNETT, Susan; LEFEVERE, André. Translation/ History/ Culture: a sourcebook. Routledge: Nova Iorque. 1992.

NYBERG, Amy Kiste. Comics Code History: The Seal of Approval. Disponível em: http://cbldf.org/comics-code-history-the-seal-of-approval/. Acesso: 30 de setembro de 2020 .

ROSA, Gisele Marion. As potencialidades de criação, legitimação e ruptura com estereótipos na tradução de histórias em quadrinhos. Escola de Comunicações e Artes, Universidade de São Paulo, 2013.

TYNION IV, James; ilustração: DELL'EDERA, Werther. Something is killing the children. Boom! Studios, 2019.

VENUTI, Lawrence. The translator's invisibility: a history of translation. London/New York: Routledge, 1995.

ZANETTIN, Federico. Comics in translation: an overview. 2008.

ZANETTIN, Federico. Translating comics and Graphic Novels, 2018. In: CÓRTES, Ovid Carbonell; HARDING, Sue-Ann. The Routledge handbook of translation and culture. Routledge Handbooks; 1 ed. 2018, p.445 - 456. 